\title{
GEOGRAFÍA FÍSICA O CIENCIAS NATURALES
}

\author{
Jesús García Fernández \\ Universidad de Valladolid
}

\section{RESUMEN}

La reflexión sobre las disciplinas científicas es fundamental para el avance del saber. Sin la duda, no hay avance científico. En este artículo se reflexiona sobre los conceptos de geografía y geografía física. A partir de una visión antropocéntrica de la geografía - la única posible - se presentan ideas básicas sobre los contenidos, métodos de trabajo y significado de las diversas ramas de la geografía física en la actualidad.

Palabras clave: Geografía, geografía física, ciencias naturales, medio físico.

\begin{abstract}
Thinking about scientific matters is basic to knowledge growth. Without doubt, there is no scientific progress. This paper analizes geography and physical geography concepts. From a anthropocentrical view of geography - the only one is possible-, basic ideas are presented about contents, framework and meaning of different points of views of physical geography.
\end{abstract}

Key words: Geography, physical geography, natural sciences, environment.

Titulo este artículo Geografía Física o Ciencias Naturales, y no como se enuncia normalmente, Geografía Física y Ciencias de la Naturaleza. Es un primer toque de atención. Puesto que la última formulación es sinónimo de que son algo distinto. En cambio, la primera introduce duda. Hace pensar; y esto es precisamente lo que trato de demostrar, que son lo mismo, pues de la una se pasa a las otras sin solución de continuidad.

Pero antes es previo hacer otra aclaración. Una cuestión es la geografía académica; y otra, la realidad que presenta la superficie terrestre. La primera es necesaria, como propedéutica; es decir, como una información inexcusable. Pero también hay que señalar que, frecuentemente, devala de la realidad; y en la práctica cotidiana enseñamos los hechos cómo no son. Sólo volviendo a aquélla, y reflexionando, encontramos cómo son. Esto no es un juego de palabras; va a los propios fundamentos de la geografía. Por exigencias de la enseñanza la hemos fragmentado en asignaturas; no es necesario mencionar su innúmero elenco. De éstas, las principales son una abstracción de la realidad; pero con fundamento 
en ella. Otras, bastantes de las más novedosas, no son lo que hay, sino lo que no hay. Tampoco es un juego de palabras. Lo que sí parece cierto es que, en vez de una aclaración, y lo es, todo hace pensar que introduzco un embolismo.

Para clarificarlo, empezaré haciendo una afirmación sorprendente, dado el título de mi intervención, y mi atribución administrativa a esta área de enseñanza. Tal aserto es, que la geografía es por esencia geografía humana. Esto que es un axioma, ha llegado a ser por desgracia, algo que hay que demostrar; ya que lo más frecuente, y bajo la influencia incoercible del academicismo, se niega la evidencia.

$\mathrm{Si}$ se vuelve a la realidad, y se analiza con la frialdad de la razón, lo que se encuentra sobre la superficie terrestre es siempre un territorio organizado con una fisonomía particular un paisaje se decía antes y reflejo de una civilización. Organización supone una sociedad, jerarquizada, que precisamente por eso, tiene capacidad de decisión, de establecer un orden, aunque parezca un desorden; pero siempre hay un orden. En esto reside una civilización, que tiene poder para organizar un territorio. Es algo que hunde sus raíces en tiempos históricos muy alejados. Así, el territorio está transformado desde hace ya milenios. Cuando hoy hablamos de organización del territorio, queremos expresar, que tiene que ser reorganizado ante las deficiencias que presenta la organización precedente es lo que no hay; pero que puede ser.

Ahora bien, no hay una organización sobre la faz de la Tierra, sino un piélago. Es lo inherente a ella; y no puede ser de otro modo. Cambian en mayor o menor escala los elementos abióticos relieve, clima, circulación de las aguas, y los bióticos vegetación, suelos. Pero sobre todo lo que varía es la valoración, que lo mismo en el pasado que en el presente, han hecho las sociedades de estos elementos, transformándolos, y por tanto humanizandolos. Son las regiones, que si descansan sobre una base ecológica siempre, han tenido una motivación muy distinta de la natural. Hay que recordar, que la palabra latina de regionis deriva del verbo rego, is, ere ... regir; y que regir es organizar. La región, que es la forma más perceptible de la superficie terrestre, es un hecho netamente humano. Por eso hay una copia innumerable de organizaciones, de regiones.

De este modo se puede afirmar, que si la geografía es esencialmente geografía humana, es también sobre todo geografía regional, aunque ahora se la denomine análisis geográfico regional. Claro, que yo me estoy refiriendo a lo que son los fundamentos de la geografía, y no a las facecias academicistas.

La geografía jamás puede desprenderse de una concepción antropocéntrica. Incluso en donde la naturaleza impone su tiranía: el dominio del frío en las zonas polares y en las elevadas altitudes, y en el dominio de la sequedad en los desiertos son los anecúmenes. Las áreas poco o nada pobladas, que si adquieren significado es por relación a los ecúmenes, los territorios poblados por distintas sociedades — civilizaciones- que los han transformado y humanizado.

Ahora bien, en una geografía de concepción antropocéntrica ¿Qué significado tiene una geografía física? Esto será el parérgon de mi intervención. Pero para llegar a este significado hay que saber previamente lo que es la geografía física y lo que se entiende por tal.

\section{Hacia el concepto de geografía física}

Su concepto desde el punto de vista académico, que se ha impuesto en la geografía, aparece como lábil y hasta contradictorio. Son las asignaturas, que figuran en todos los planes de estudio: la geomorfología, la climatología, la hidrología y la biogeografía. Con el tiempo, en vez de ser partes de un todo, han llegado a ser todas aparte. No existe conexión entre ellas; 
sus explicantes valga la expresión se han hecho especialistas en cada una de éstas. Con el afán de profundizar, cuando no por comodidad, se han metido en un pozo, desde cuyo fondo no se ve más que el círculo zarco del cielo; y efectivamente, están en el «cielo»; no en la tierra. Entre sí, con un lenguaje críptico no se entienden más que un alumno de la licenciatura. Tampoco se hacen la pregunta de que es lo que vincula a todas ellas. No es cuestión que les preocupe; cada uno va a lo suyo. La geografía ¿qué geografía? les une. Es más, algunos de ellos la niegan en cuanto tal; las encuadran en las ciencias geográficas (sic). Lo que sí es común a todos, es haber entrado a saco en otras ciencias. Incluso son vergonzantes de sus orígenes; y se denominan geomorfólogos, biogeógrafos, etc.

En un plano superior, cuando quieren dar fundamentos a sus respectivas «ciencias», o cuando se trata de capturar trabajos de «geografía aplicada», se habla de medio físico, medio ecológico o paisajes, entendidos como los elementos que pertenecen a la naturaleza. Pero más que como un conjunto trabado, como elementos separados; que, además, son tratados de un modo parcial, y hasta superficial. Por eso los estudios del medio físico no son patrimonio exclusivo de los geógrafos; cualquier cultor de las ciencias naturales, cuando no un quídam osado, se atreve a realizar estudios del medio físico. Naturalmente cada uno de éstos resalta lo que conoce, y lo demás es acarreo de segunda mano, que se utiliza con avilantez y de modo chirle.

Más enjundia parece tener lo que desde hace unos años se denomina Geografía Global un solecismo que espanta, porque global se refiere al Globo, a la Tierra como planeta. Por eso, también se le ha dado el nombre de geografía integral. No es integrada, sino el estudio independiente de los elementos que componen el medio físico, frecuentemente realizado por diferentes especialistas sin conexión. Cómo forman un todo en el que los diferentes elementos están lañados entre sí, eso queda para que lo deduzca el lector, si es capaz. Cambian los nombres; pero los hábitos permanecen.

En España esta orientación ha tomado la denominación de ciencia del paisaje, paisaje integrado o simplemente paisaje. Entró a comienzo de los años setenta, como un mimetismo simiesco de las ideas de un geógrafo francés, que buscó su inspiración en una época en la que hasta la ciencia tenía que ser marxista, en la entonces Unión Soviética, que a su vez lo había hecho en la Landschaftökologie del eminente geógrafo alemán C. Troll. Del landschaft se pasó en francés al paisaje. Desde entonces los geógrafos españoles creen haber encontrado la clave de la geografía física. Con una cierta transposición del mencionado francés conceptúan el paisaje «como una interrelación un buen galicismo» entre los elementos abióticos, que crean un potencial ecológico, que tiene su aprovechamiento en una combinación biológica bajo la intervención antrópica otro neologismo y que, por tanto, es «dinámica». Su fin es el estudio de los «geosistemas», una transposición del viejo concepto de A.G. Tansley (1939) de «ecosistema», revivido por los biólogos unos cuarenta años después.

Pero, en realidad, esta concepción, más que una geografía física integrada, es un modo de utilizar los elementos del medio físico, más bien algunos, para explicar la vegetación en su dinámica propia. Por eso pone más énfasis en las «geofacies» que en los «geosistemas» ${ }^{1}$. Nada tiene de particular, por tanto, que haya sido practicado por algunos biogeógrafos. Pero también el paisaje es objeto de muchos biólogos, que dentro de los «ecosistemas» lo emplean, más que para la vegetación, para comprender las cadenas tróficas del complejo

1 La base teórica de esta concepción en BERTRAND, G. (1968): «Paysage et geographie physique globale. Esquisse methodologique», en Revue Geographique des Pyrénnés et du Sud-Ouest, T.39. pp. 249-272. 
mundo de la zoología ${ }^{2}$. Así mismo, del paisaje se ha pasado al paisajismo por su valoración estética y como recurso natural, inserto en eso tan ambiguo del desarrollo rural.

De este modo no es que el paisaje como ciencia se haya ampliado, sino que se ha trivializado. Lo más grave es que ha trascendido a los geógrafos. En un libro reciente se dice, que también los animales forman parte del paisaje ${ }^{3}$. En otro se defiende, que los geógrafos tenemos que recuperarlo en su orientación de paisajismo ${ }^{4}$.

De todo esto se obtiene la conclusión de que no existe un concepto claro de geografía física. Ni como medio físico, ni como paisaje, versus vegetación, sino un conjunto de geografías físicas individualizadas cada una con sus métodos propios y objetivo exclusivo. La geografía física así no es más que un nombre. El academicismo ha triunfado sobre la realidad. Pero, además, hay que considerar, qué es lo que hay de geografía en estas geografías.

\section{El embeleco de las geografías físicas}

No se puede admitir, como frecuentemente se ha hecho, el apotegma de que «geografía es lo que hacen los geógrafos». Esta es una petición de principio. Los geógrafos pueden no hacer geografía; y de facto es así en muchos casos. Centrándonos en nuestro tema ahora, hay que dar por cierto, que los llamados geógrafos físicos en vez de inspirarse en lo que es su objetivo con su propia dialéctica, han incorporado, o mejor dicho, se han apropiado, de los métodos de otras ciencias de la tierra y de su orientación. No deja de haber una relación; pero colaboración no significa confusión. Veamos cómo actúan para que cada uno saque sus conclusiones.

a) Relieve o geomorfología. Esta es una primera recuesta. Hay que precisar, que la palabra «geomorfología» fue acuñada por dos geólogos yanquis, W.D. McGee y J.W. Powel hacia 1880. Si nos atenemos al significado étimo del término, su objetivo parece claro. Según los vocablos griegos «geos=tierra», «morfos=forma» y «logos=dialéctica=tratado», la geomorfología sería el estudio de las formas de la tierra. Tales formas, como algo destacado en la configuración de la superficie terrestre, sería el relieve. Así se concibió en la Europa continental; el conocimiento del relieve se denominaba hasta los años sesenta simplemente morfología. Entonces esta última palabra, por considerarse poco científica, se sustituyó por la anglosajona. Aún así siguió teniendo por objeto el relieve; y todavía se sigue formulando de este modo.

Otra cuestión es que sea lo que se hace; pues con esta adopción todo se empezó a engarbullar. Desde la creación de la palabra en los países anglosajones, se define como el estudio de las «lands forms», equivalente a formas de terreno. Ni land es Tierra; ni forms se refiere al relieve. Palabra que tiene otro significado en inglés, y que sólo como relief, importada del francés, se utiliza muy ocasionalmente por los geógrafos anglosajones; y las «lands forms» son una jarcia en la que entra todo, desde la escala métrica, cuando no centimétrica, hasta la kilométrica.

Sin embargo, en Europa, y en particular en España, el relieve ha continuado siendo el objetivo de la Geomorfología. Pero, ¿en realidad se estudia el relieve? Para poder discernirlo es preciso saber, qué se ha de entender por relieve.

2 En este aspecto es expresivo el libro también inspirado en los científicos soviéticos de GONZÁLEZ BERNÁLDEZ, F. (1981): Ecología y paisaje. Ed. Blume. Madrid, 250 pp.

3 GÓMEZ MENDOZA, J. (dir.), MATA OLMO, R. et al. (1999): Los paisajes naturales de Madrid: naturaleza y medio rural. Fundación Caja Madrid. Alianza Editorial. 301 pp. Cf./ pp. 107.

4 VV.AA. (1998): Paisaje y medio ambiente. Universidad de Valladolid, 150 pp. 
En el sentido etimológico en español, se entiende como lo que resalta sobre un plano. Aplicado a la geografía, y tomando como plano el nivel del mar, son las desigualdades, que en más o menos destacan por sus dimensiones, altitudes, desniveles y pendientes. Son los elementos que de modo tridimensional configuran a gran escala un sector de mayores o menores dimensiones de las superficies continentales. Son las formas de relieve, que en conjunto constituyen la infraestructura, el relieve de un territorio: Galicia, España, Europa, la Tierra. Siempre están constituidas por grandes unidades morfoestructurales. Son algo complejo y variado, que están integradas por otras formas de menor escala los elementos del relieve, lo que generalmente se estudia como propedéutica para poder abordar el relieve de un sector: una comarca, una región o un área de mayor extensión.

Estas formas de relieve, se enuncia siempre así, son el resultado de dos fuerzas opuestas, pero que actúan de consuno. Las endógenas construyen, mientras que en las externas la erosión en sentido lato tiende a retocarlas, e incluso a destruirlas. Cuando en esta acción dual, y a escala del tiempo geológico reflejan las iniciales son las morfoestructuras, en las que no faltan detalles, y hasta formas que se deben a la erosión, son el modelado, las morfoesculturas. Ambas fuerzas de modo concomitante originan las formas de relieve. Este es el objeto de la llamada geomorfología estructural, sólo mencionada y frecuentemente pretérita.

Pues, si este es un planteamiento correcto, otro axioma, se ha desarrollado de modo unilateral. Desde los comienzos de la geografía moderna, y por imitación de los geólogos, cuya finalidad era muy distinta, se ha alzaprimado la erosión y los procesos que la originan. En la práctica lo que se ha estudiado son las formas erosivas. El relieve ha quedado postergado a geologismos, que nada explican. No han faltado algunos geógrafos, pocos, que se dieran cuenta de la contradicción entre lo que hacían y el planteamiento. Presos de su formación, o mejor dicho de su deformación, han resuelto la paradoja de manera unilateral, y la geomorfología es el estudio del modelado del relieve, y ¿el relieve? ¡Averígüelo, Vargas!

Si esta solución adarva por completo, todavía ataranta más la orientación que en los últimos años ha tomado la geomorfología bajo el imperio de los anglosajones. Como la elaboración de las formas erosivas exige millones de años, y se han superpuesto muy diferentes condiciones ecológicas, imposible de emparentarlas con las actuales, su estudio adolece de conjetural; y por tanto, tiene que ser rechazado. De todo lo que no se tenga evidencia en el tiempo, y de los procesos que han originado las formas, debe de ser condenado al disparatario. Así la geomorfología ha quedado limitada a dos series de cuestiones.

En formas, las correspondientes al Pleistoceno, porque a través de los procesos, que hoy se conocen (sic), se tiene la certeza de cómo se elaboraron, se puede establecer su cronología y ser medidos con precisión: el modelado glaciar y el periglaciar. Fuera de esto, lo que interesa son los procesos en sí mismos, y sobre todo en su evolución cuantitativa. Así, la medición de la ablación de las laderas, sus deslizamientos y derrumbamientos; los cambios en los lechos fluviales; los proceso eólicos; la abrasión y acumulación marina; la descomposición de las rocas, y la disolución en calizas, constituyen los temas principales en que están azacaneados los geomorfólogos. Medición y experimentación han engendrado, más que métodos, complejas técnicas, sofisticadas y hasta absurdas, como la simulación de la lluvia. Siempre en espacios reducidos, que rara vez llegan a un kilómetro, cuando no es en los laboratorios 5 . Ya no es, ni siquiera el modelado.

5 Véase sobre esta orientación, HART, M.G. (1986): Geomorphology pure and applied. George Alle and Urbin. Londres, 228 pp.; y KLARK, M.J. et al. (1987): Horizonts in physical geography. McMillan. Londres, $395 \mathrm{pp}$. 
Semejante orientación, que se inició a finales de los años setenta, se ha ido imponiendo progresivamente hasta ser la geomorfología por excelencia. España no podía ser menos. Cuaternario y procesos son una misma «ciencia». Se justifica, porque del plano teórico se puede pasar al aplicado con el fin de predecir y evitar desastres, y ¡ cómo no! contribuir a la mejora del medio ambiente. Geomorfología pura y geomorfología aplicada son complementarias. Yo no sé, como esta última ha sido útil a la sociedad; lo que sí es cierto, que ha permitido publicar muchos papers; y que ha sido un medio cómodo de embarnecer muchos currículums.

En cuanto al significado que puede tener este estudio de los procesos es todavía incierto. Para el pasado, con el fin de explicar las formas del modelado es inútil, ni siquiera se intenta, se desconocen las variables que puedan haber intervenido. Y para el futuro, dada la lentitud de los procesos, y a través de los reducidos espacios de experimentación, quizá dentro de un milenio se haya llegado a unas conclusiones certeras. De ellas se aprovecharán, si es que todavía existen, los geógrafos de esa época. Nosotros no tendremos esa suerte, porque estaremos todos en la huesa.

Es evidente que esta geomorfología, pura o aplicada, en nada contribuye al conocimiento de las formas de relieve; y mucho menos al del relieve de la superficie terrestre, lo verdaderamente geográfico. Pero, además, no es algo exclusivo de los geógrafos. En este nuevo quehacer intervienen técnicos ingenieros, que son los que han hecho las primeras aportaciones, y geólogos. En este aspecto es bien expresivo que, en una publicación reciente sobre la contribución española a la geomorfología, aparezcan en el mismo saco unos y otros $^{6}$. Nada tiene de particular; porque sus cultivadores precisan, que la geomorfología es una ciencia de por sí con sus métodos y objetivos propios. Entre los españoles es frecuente oírles, que tienen más que ver con la geología y las ciencias de la naturaleza, que no con la geografía.

Hay que concluir, por tanto, que esta nueva tendencia, que ha llegado a ser la geomorfología por excelencia, no sólo no permite llegar al conocimiento del relieve, sino que se ha apartado por completo de la geografía; de una geografía, itero, que no puede desprenderse de su concepción antropocéntrica.

b) Climatología o análisis geográfico del clima. También el clima, que indiscutiblemente es un hecho geográfico, es objeto de los cultores de otras ciencias. Los meteorólogos parecen ser los más indicados para el cultivo de la climatología; los agrónomos la practican como agroclimatología; los biólogos lo tienen siempre como un punto de referencia; y los físicos más recientemente han entrado en él con las teleconexiones. Pero dejando a éstos con sus facecias, lo que hay de común en todos ellos es considerar al clima como un hecho meramente físico; y todavía muy atraillado a la primera concepción del estado medio de la atmósfera.

Se continúa con inercia, en los más de los casos, en evaluarlo casi exclusivamente por las temperaturas y precipitaciones medias anuales; algunas mensuales más expresivas Enero y Julio para las segundas y el régimen térmico o pluviométrico. A veces se precisa con las máximas y mínimas absolutas, aunque más bien se recurre a sus valores medios. Muy frecuentemente, en las regiones o naciones en las que las precipitaciones son parcas a lo largo del año, o en parte de él, se intenta medir la aridez con métodos siempre imprecisos, y que sólo tienen de indicativos. Se confunde el clima con estos datos; cuando son más

6 GARCÍA RUIZ, J.M. (1999): La producción científica de la geomorfología española y su impacto a través de las publicaciones periódicas. Instituto Pirenaico de Ecología. CSIC. Zaragoza, 104 pp. 
bien un medio de expresarlo, y bastante chanflón. Pues se omiten otros hechos generalmente, que tienen una gran importancia para la actividad o vida humana: el viento, la nivosidad e innivación en las montañas; las nieblas, boiras o calígines; los rocíos, escarchas y cencelladas; y las brisas marinas o terrales.

Se aduce, y es cierto, que de estos aspectos del clima faltan datos en los observatorios. Lo que no deja de ser una muestra bien patente de la parcialidad con la que se analiza el clima. Pero también lo es el conformismo con el punto de partida de su concepción.

Ahora bien, tampoco es cierto que, aunque se continúe con esta inercia, no se hayan introducido otros hechos que han contribuido tanto a precisar, como a explicar el clima. Me refiero a la circulación atmosférica que, después de descubrirse el Jet del frente polar, ha abierto grandes perspectivas en los conocimientos del Hemisferio septentrional. Menos atención ha merecido el East jet tropical, que está siendo preterido por otros fenómenos meteorológicos más espectaculares, aunque deriven de sus variaciones.

Sin embargo, en la circulación atmosférica se ha puesto más énfasis en el aspecto meteorológico para predecir o explicar situaciones que aparentemente son excepcionales, que no en la gran variedad de tipos de tiempo que origina. Me estoy refiriendo, no a sus conocimientos a escala general, es decir, al clima como asignatura, que lo mismo en el extranjero, que en España, cuenta con excelentes tratados ${ }^{7}$. Mi alusión está dirigida al quehacer concreto de los que se ocupan del clima, todos los que he mencionado al principio.

En este aspecto mi observación va encaminada a señalar que, pese a la gran diversidad de tipos de tiempo que origina la circulación atmosférica, por su repetición con mayor o menor frecuencia, es la variedad lo que por paradoja crea un ambiente permanente con sus matices siempre importantes por la incidencia que tienen. Además, los tipos de tiempo es lo que permite el análisis no sólo de temperaturas y precipitaciones, sino la combinación de éstos con todos los otros, que acabo de mencionar, y que quedan elididos.

Pero para lograr este modo de conocimiento es necesario también tener en cuenta otro hecho, que nada tiene de meteorológico, pero sí una influencia en el clima. Me refiero al relieve en su configuración a gran escala, y aún a menor como en las montañas. Pues el relieve origina, que los efectos de la circulación, los tipos de tiempo, sean muy diferentes en la combinación de sus elementos meteorológicos. De este modo, a escala regional lo que se denominan «climas locales» y aun «microclimas» es como pueden tener transcendencia no sólo ecológica, sino también en el territorio organizado. Pues desde hace poco más de un siglo, y sobre todo en la actualidad, ha sido valorado lo mismo en el aprovechamiento agrario, que en las dotaciones urbanas. En épocas anteriores, aunque no dejaba de tenerse en cuenta, mediaban otros factores, que tenían muy poco de naturales. Es con esta orientación cómo el análisis del clima deja de ser meramente físico para entrar en una concepción antropocéntrica, geográfica.

Se puede preguntar, si es esto lo que hacen los geógrafos. La respuesta es, que sólo de forma muy parcial. Muchos siguen evaluando el clima por los valores medios de precipitaciones y temperaturas. En cuanto a los geógrafos que más atención le dedican, los especialistas han variado de temas según cambiaban las modas, introducidas por los climatólogos/meteorólogos. Hace unas décadas fue la dinámica atmosférica, en la que hubo importantes aportaciones; pero más como un hecho en sí y a escala de toda España, que no en los tipos de tiempo que ocasionaban en los dominios o conjuntos ecológicos. No

7 Entre otros se puede mencionar, GIL OLCINA, A. y OLCINA CANTOS, J. (1997): Climatología General. Ed. Ariel. Barcelona, 579 pp.; y CUADRAT, J.Ma . y PITA, Mª F. (1997): Climatología. Ed. Cátedra. Madrid, $496 \mathrm{pp}$. 
obstante no faltaron excepciones ${ }^{8}$. Pero sin que se hubiera agotado esta preocupación, han sido otros los temas en los que se han centrado las investigaciones.

En los últimos cuatro lustros uno de ellos ha sido el tratamiento estadístico de temperaturas y precipitaciones con el fin de averiguar los períodos de retorno de hechos singulares, que tienen una incidencia negativa para predecir lo que nos espera en el futuro. Es otro aspecto de geografía física aplicada. Claro, que en éste a los geógrafos les habían precedido los técnicos ingenieros principalmente, que si ya habían cosechado fracasos verdaderamente estrepitosos, los geógrafos no se han arredrado en seguir este camino errado. Otro tema muy de actualidad ha sido el estudio del clima urbano; pero en realidad se ha reducido a la llamada isla de calor. Para ello se han empleado métodos muy rudimentarios; otros más sofisticados como la irradiación de los datos codificados de satélites con complicadas técnicas para transformarlos en temperaturas. Han logrado resultados, que no pasan de lo que ya se sabía por experiencia. Su única aportación ha sido darles un valor cuantitativo, y no siempre ${ }^{10}$.

Si esta cuestión nos llegó del otro lado del Atlántico, encuadrada en ese paradigma, que pone su énfasis en las repercusiones negativas que la sociedad actual ha provocado en el medio físico el environment; en España medio ambiente. Otra nos ha llegado de la propia nación: los cambios en el clima. Creo, que el primer precedente fue la de un historiador francés en un libro de tanto éxito como farragoso, y en el que los hechos se prestan a muy diferentes interpretaciones ${ }^{11}$. En España no faltaron algunos precursores. Uno en los años cincuenta; otro en los setenta. Ambos dos diletantes. El primero en un libro que expuso teorías verdaderamente descabelladas; el otro en un centón de tipos de tiempo catastróficos. Su influencia, sin embargo, fue escasa. Pero cuando un prestigioso meteorólogo, ya a finales de los años ochenta, publicó una Historia del clima en España, bastante conjetural, fue el clarín de atención para los geógrafos ${ }^{12}$.

Algunos de ellos, con el empleo de documentación y con muy sutiles interpretaciones, más que aclararnos, nos han llevado a la confusión. Han demostrado más ingenio que resultados apodícticos. Tampoco han prescindido de la teoría más sensacionalista y alarmante del «cambio climático»o «calentamiento del globo», aunque para repetir lo mucho publicado sin cuestionarlo; pero sin que falten algunos que han hecho importantes precisiones ${ }^{13}$.

Mientras los geógrafos están entruchados en estas bagatelas, hay problemas del clima de España que permanecen en el más completo olvido. Aparte de un conocimiento más acendrado de los climas regionales mediante los tipos de tiempo, que aclararían muchos de los matices que los singularizan, señalaré algunos. Los climas de montaña, ese verdadero

8 Por ejemplo, ORTEGA VILLAZÁN, Ma T. (1992): El clima del sector Norte de la Cordillera Ibérica. Estudio geográfico. Universidad de Valladolid, 359 pp.; y CASTILLO REQUENA, J. (1981): «Mecanismos de precipitación en Sierra Nevada», en Cuadernos Geográficos, n ${ }^{\circ}$. Universidad de Granada, pp. 127-152.

9 CLAVERO, P., MARTÍN VIDE, J. y RASO, J.Ma . (1982): «La climatología actual: el uso de métodos estadísticos y modelos probabilísticos» en Notes de Geografía Física. Barcelona, pp. 510; CLAVERO PARICIO, P. (1983): «Probabilidades de precipitaciones intensas en diversos observatorios de Cataluña» en Notes de Geografía Física, no 9. Barcelona, pp. 33-38; y MARTÍN VIDE, J. (1990): «Las técnicas cuantitativas en geografía física española de los años 80. Una aplicación al cálculo de probabilidades en climatología» en IV Coloquio de Geografía Cuantitativa. Palma de Mallorca. pp. 299-310.

10 LÓPEZ GÓMEZ, A. (Coord.), FERNÁNDEZ GARCÍA, F., ARROY ILLERA, F., MARTÍN VIDE, J. y CUADRAT, J.Mª. (1993): El clima de las ciudades españolas. Ed. Cátedra. Madrid, 262 pp.

11 LE ROY LADURIE, Emmanuel (1991): Historia del clima desde el año mil (Trad. de francés de 1983). Fondo de Cultura Económica. México, 515 pp.

12 FONT TULLOT, I. (1988): Historia del clima en España. Instituto Nacional de Meteorología. Madrid, 297 pp. 
mosaico en el que se encuentran muchas sorpresas, como, por ejemplo, ese máximo de precipitaciones en el verano del sector oriental de Los Pirineos. Se debe de dilucidar, si son el resultado de fuertes tormentas de gran intensidad horaria de escaso valor ecológico o si son algo continuado. Se podría averiguar así, qué es lo que tiene más importancia, si las de invierno, más persistentes con importante nivosidad, o las estivales. No es cuestión baladí, pues su transcendencia ecológica desde el punto de vista humano no es la misma. Aclarará, sin duda, el significado que tiene el clima en las nuevas actividades (estaciones de esquí, poblamiento de temporada estival, turismo), que han transformado de modo muy importante la vida de este sector montañoso.

Otro problema a dilucidar es el de los veranos de la España Atlántica la Iberia húmeda de J. Brunhes o la España siempre húmeda de H. Lautensach. ¿Son tan continuadas las lluvias como se afirma o en el verdor que la caracteriza intervienen otros elementos meteorológicos brisas marinas, condensación orográfica, calígine, nieblas, inversiones térmicas en relación con el relieve? Se podría saber también con precisión, si esa aridez estival del SO. de Galicia, señalada por algunos que se han ocupado de su clima, y de la que se han hecho eco los geógrafos, es tal, o es un interés, también una queja, para que el Estado fomente el regadío, que aumenta de un modo sensacional los rendimientos agrarios en el sector en el que la explotación agraria alcanza una intensidad verdaderamente increíble ${ }^{14}$.

Estos, entre otros problemas, son algo que no entra dentro de la mentalidad de los climatólogosmeteorólogos, y que sólo pueden resolver los geógrafos con una concepción antropocéntrica del clima. Para ello es necesario que, en vez de ser sus epígonos, sean realmente geógrafos.

c) La hidrología una gran olvidada. En el clima, pese a seguir la pauta de los climatólogos, los geógrafos no han dejado de hacer contribuciones importantes; pero en la hidrología han sido, salvo contadas excepciones, tributarios de otros especialistas, precisamente cuando no deja de sonar la cantinela, que el agua es un bien escaso. En este aspecto aún estamos apegados al comienzo, cuando un ingeniero hidráulico, M. Pardé, marcó la pauta para la geografía hace ya más de cincuenta años. Casi en parigual que los hidrólogos, todo se centra en el caudal de los ríos importantes: módulo absoluto y relativo, antes medidos en $\mathrm{m}^{3}$ y hoy en $\mathrm{hm}^{3}$; el régimen hidrológico; estiajes y crecidas. Pero los estudios en los más de los casos son un mero expediente para obviar un vacío, que sigue estando hueco.

Hoy se pone énfasis en los recursos hidrológicos; pero casi todo se orienta hacia el regadío. Sin embargo, hay otra clase de aprovechamientos de gran importancia geográfica: abastecimientos, energía hidroeléctrica, que los geógrafos solo abordan de segunda mano, y sin espíritu crítico; es decir, sin los debidos conocimientos; al igual que la regulación de las cuencas hidrográficas y el almacenamiento de agua para obviar las irregularidades de las precipitaciones o la necesaria para la producción de hidroelectricidad en grandes presas. Sobre todos estos aspectos se pasa por ascuas. Aunque en esta cuestión también hay excepciones $^{15}$.

13 Sobre todas estas cuestiones a barrisco son expresivas dos obras: MARZOL, Ma.V., DORTA, P. y VALLADARES, P. (eds.) (1996): Clima y agua. La gestión de un recurso climático. Ed. Tabapress, Madrid, 398 pp. y RASO NADAL, J.M. y MARTÍN VIDE, J. (eds.) (1999): La climatología en los albores del siglo XXI. Asociación Española de Climatología. Barcelona, 587 pp.

14 Véase DÍAZ FIERROSVIQUEIRA, F. (1971): Contribución a la climatología agrícola de Galicia. Universidad de Santiago de Compostela. 110 pp.; y BOUHIER, A. (1979): La Galice. Essai géographique d'analyse et de interprétation d'un vieux complexe agraire. La Rochesur-Yon (Vandée). 2 vols.

15 Este es el caso del Instituto Universitario de Geografía de la Universidad de Alicante en el que algunos de sus integrantes, como GIL OLCINA, A., MORALES GIL, A., VERA REBOLLO, F. y RICO AMORÓS, A., 
Ahora bien, igualmente hay que señalar que, por seguir a los hidrólogos, los geógrafos se han ocupado casi exclusivamente de los cursos fluviales, y han dejado en olvido otros aspectos de la hidrología. Uno de ellos es la circulación de las aguas de escorrentía, que sólo han merecido consideración para los geomorfólogos de los procesos con la andrómina del splash y las formas de arroyamiento; pero no en cuanto a sus caudales. En cambio, nula atención se ha puesto en especificar como originan el complejo absorbente con la circulación subálvea, que tiene un valor capital como factor ecológico. Y en ambos hechos, isí que caben experimentos, medidas y aparatos!

También la contribución de los geógrafos en los recursos de las aguas hipogeas, más que escasa, ha sido cenceña. Parece que es una cuestión de los llamados hidrogeólogos. Pero los acuíferos, más que estar en relación con las litofacies, dependen de la estructura de éstas en los elementos del relieve. Aquí hay un camino en realidad inédito para los hidrogeógrafos, que pueden hacer aportaciones importantes que sirvan de base para ingenieros de minas y geólogos, que hasta ahora parecen tener la exclusiva. Hay que cambiar las tornas; pero para eso es necesario que los geógrafos adquieran un conocimiento de las formas de relieve que, como se ha podido percatar, ahora rechazan.

Hay que concluir, por tanto, que la hidrología es la gran olvidada de la geografía física. Pero, si en este hecho geográfico sus cultivadores (sic) han sido miméticos de los ingenieros, en la biogeografía se confunden con los botánicos.

d) Biogeografía versus botánica. Con esta expresión se ha comenzado por recuperar una palabra decimonónica, que tiene el sentido de lo más peyorativo, que se pueda concebir en geografía. Fue acuñada para dar a conocer cómo se distribuían las plantas y los animales en superficie. En una época en la que todo lo que se podía reconocer sobre un mapa precisemos, un cartograma era «geográfico», y no precisamente en relación con su hábitat la ecología de Haeckel (1886), sino como algo meramente descriptivo. Lleva el tórculo de una primitiva biología. Se comprende ahora por qué hay geógrafos que consideran que la fauna forma también parte del paisaje; y que algunos se esfuercen en incluirla en la biogeografía.

Pero aún sin llegar a estos extremos siempre resulta difícil, por no decir imposible, hacer la distinción entre lo que es botánica y geografía. En el caso más sencillo, las comunidades vegetales se definen por el conjunto de sus especies. En una formación arbórea, y con una asociación bien caracterizada por su biotipo, junto a los árboles aparecen todas las especies, que constituyen el subvuelo, que naturalmente son las más numerosas. En un recorrido o en varios, depende del interés que se ponga, se hace un inventario, prescindiendo de los nombres vernáculos, y todo lo más se realizan índices de frecuencia, generalmente de modo simplista: rara, abundante, muy abundante. Todo ello a granel, aparece sin especificar mucho. Tras esta retahíla de nombres latinos se llega a la conclusión, que no es que los árboles impidan ver el bosque, sino que las plantas enmascaran los árboles y el bosque. A esto se llama paisaje; y a veces para hacerlo más expresivo se recurre a gráficos, que se denominan pirámides, que de ello tienen poco, y sí de grotescos dibujos.

Como las masas de vegetación varían de unos lugares a otros y muy frecuentemente entreveradas, se recurre a las precipitaciones y temperaturas con datos de observatorios, que a veces están muy distantes; y cuando esto no es posible se deduce de la misma vege-

que en distintas publicaciones han dado a conocer la distribución del agua en el SE., las avenidas de los ríos, su régimen hidrológico, los recursos hipógeos y la propiedad del agua en esta región. Así mismo este Instituto ha organizado reuniones sobre Avenidas fluviales e inundaciones en la cuenca del mar Mediterráneo (1989), Demanda y economía del agua en España (1998), y Usos del agua en España (1999). 
tación. Si hay tal planta tiene que haber tal clima; y si hay tal clima tiene que haber tal planta. Es una inducción desmesurada. Pero hay casos, que ni así cuadran los esquemas. Entonces se recurre a los suelos, más bien a las litofacies alteradas. En este aspecto hay un botánico, muy seguido por algunos geógrafos, que afirma que con algunas especies puede señalar el límite exacto entre la España Atlántica y la España Mediterránea. No deja de ser sorprendente; y no se sabe si admirar más tal precisión o la avilantez en señalarla. A mí ante este mecanicismo ecológico recíproco, me viene a las mientes aquello «de si es con barbas San José; y si no la Purísima», aunque sea como una hipérbole.

Pero recientemente, y con más arraigo entre los geógrafos, ha ido ganando adeptos la escuela de la sinfitosociología, de cuyas ideas en parte participan los biogeógrafos de la fitogeografía. Los primeros para un gran conjunto de grandes dimensiones, como es España, por trasposición de las cliseries montañosas, lo han dividido en pisos y provincias (sic) a base de fórmulas simplistas y a la vez complejas, que denominan índices climáticos. A ellos les aplican un determinado tipo de vegetación. Si lo hay, y es aviniente con ellos, definen las asociaciones vegetales. Pero invirtiendo el concepto tradicional, no por lo que es dominante, que figura en segundo lugar, sino por una especie indicadora, que a veces es única, endémica o que está fuera de su área. Todo ello se expresa en una jerigonza propia de la culta latina parla. Si por haber cultivos o ser llecos no aparece la supuesta asociación es la vegetación potencial, que indica que la preexistente asociación ha desaparecido como consecuencia de la acción antrópica otro neologismo inaceptable por su falta de sentido; pero, que si ésta deja de tener semejantes efectos negativos se reconstruirá la primitiva la climácica en fases sucesivas. No es raro oír algún biogeógrafo de esta laya, si encuentra unas matas de encina en un lleco: «dentro de cien años un encinar». ¡Es el don de la profecía! Si por el contrario aparece una masa de vegetación, que no coincide con los índices climáticos, ni con los suelos, entonces es una vegetación relicta. Por ejemplo, un hayedo en medio de un quejigal. Ante tal anomalía se dice que está en condiciones disbióticas, aunque el hayedo esté en plena expansión y pujanza.

De este modo el Mapa de series de vegetación de España aparece cubierto de asociaciones en tierras de cultivo. Así, las cuestas de los páramos de los Montes de Torozos figuran como la serie supramediterránea (piso) castellano-alcarreña-manchega basófila (provincia) denominada Cephalontherolongifolial-Querceto faginae sigmetum. La Tierra de Campos, en donde no queda ningún monte, al igual que para la Tierra de Medina, donde no son raros los pinares, pertenece a la serie supramediterráneo-castellano-maestrazgomanchega definidas como Juniperethum ferae-Querceto rotundifoliae sigmetum ${ }^{16}$. Una vez más volvemos a la «ciencia de lo que no hay, haciendo caso omiso de lo que hay». Una muestra de ello es que fitosociólogos y fitogeógrafos prescinden de los pinares, que, a excepción del pino silvestre, consideran introducidos por el hombre al igual que el castaño. Esta abstracción es uno de sus dogmas, a pesar de que desde hace unos años los estudios paleobotánicos han demostrado que todos los pinos, a excepción del denominado Monterrey (Pinus insignis) son autóctonos ${ }^{17}$.

Pero, además, aplicar denominaciones de alcarreña, manchega y maestrazgo a estas tres comarcas no sólo es un dislate geográfico, sino una provocación a la geografía. Pero lo malo no son estas facecias de los fitosociólogos, sino que hay geógrafos, y hasta bioge-

16 RIVAS MARTÍNEZ, S.: Mapa de series de vegetación. ICONA.

17 BLANCO CASTRO, E. (1997): Los bosques Ibéricos: una aproximación geobotánica. Ed. Planeta. Barcelona, 572 pp. $C f$. pp. 43 y ss. 
ógrafos, que repiten esta jerigonza como papagayos. Se podrían hacer muchas citas; pero basta con una por la brevedad de la ocasión. Uno de ellos para encuadrar biogeográficamente un área del SE. a $550 \mathrm{~m}$. señala que pertenece al piso bioclimático mesomediterráneo y en la provincia castellano-maestrazgo-manchego, sector manchego, y subsector manchego manchego-espunense de la Sierra de Espuña que se encuentra bastante alejada ${ }^{18}$.

Estas denominaciones, lo mismo las de las asociaciones que sus áreas, más que logogríficas, y lo son, tienen de esperpénticas y abracadabrantes. La de provincias es un contrasentido. Aplicar una división administrativa a un conjunto de vegetación que se considera natural, sólo puede ser calificado de un marramiento de doctores indoctos. ¡Y qué decir de encuadrar a la vegetación de las montañas de la mitad septentrional, así como a la de la España Atlántica en la región eurosiberiana! Cuando hoy se sabe que durante los periodos fríos del Pleistoceno los países mediterráneos fueron refugio de especies, que a partir de la última deglaciación y en el decurso del Holoceno se fueron expandiendo hacia áreas cada vez más aquilónicas. ¡El mundo al revés!

Es lamentable que los geógrafos hayan caído en semejantes trampantojos, cuando tienen un campo inédito, y mucho más aviniente con su objetivo. En primer lugar, las masas de vegetación, por muy extensas que sean, ocupan sólo una parte del territorio. Su primera misión es averiguar por qué han conservado la localización que hoy presentan. Este es un hecho histórico, que hay que poner en relación con el aprovechamiento que tuvieron en la vida rural tradicional. También con la desamortización civil de 1855, que cambió su propiedad; y con la ley de 1863, que exceptuó de venta los montes de pino, haya y roble de más de cien hectáreas. Tampoco se puede prescindir de las repoblaciones de distintas épocas a partir de comienzos del siglo XX, y en especial las de 1940-60. Pero no sólo ha habido repoblaciones en época contemporánea. Muchas de las masas de siglos precedentes han sido plantadas o se han mantenido mediante técnicas, que por empíricas no deja de formar parte de la selvicultura.

Explicar su localización es dar un sentido real, geográfico, a la vegetación. Para definirla hay que volver a los conceptos clásicos de formaciones y asociaciones. Estas últimas expresarlas por la dominancia de sus especies: encinar-carrascal, quejigar, rebollar, robledo, hayedo, pinar, etc., precisando su nombre científico. Otro tanto hay que hacer con los matorrales: jarales, brezales, retamares, etc. Cuando son heterogéneos, y el criterio de dominancia no es expresivo, como es en las montañas del Mediterráneo, cabe la denominación de garriga castiza de todas las regiones de habla catalana. No hay que ir al recuento exhaustivo, deben de ser definidas por las especies más abundantes con los nombres vernáculos, en general muy expresivos, y los latinos.

Pero el geógrafo debe ocuparse también del porte de las formaciones y de los árboles que constituyen las asociaciones. Tiene casi todo de antropogénico. En su explotación secular se han hecho podas de acuerdo con lo que se quería obtener de ellos, que ha marcado su fisonomía. Para leña y bellota en encinares y quejigares menos en los robles: poda a horca y pendón; leña en los rebollares, tallares: corta a mata rasa. En el carboneo se han combinado en los encinares la mata rasa con los vástagos estoloníferos, son las cepedas. Otras veces y por diversas causas entre los árboles se ha dejado crecer el matorral, mohedas. La explotación en casos ha llegado al máximo, dejando reducidos encinares y rebollares a pequeñas

18 BELMONTE SERRATO, F., ROMERO DÍAZ, A. y LÓPEZ BERMÚDEZ, F. (1999): «Efectos sobre la cubierta vegetal, la escorrentía y la erosión del suelo, de la alternancia de cultivo abandono en parcelas experimentales» en Investigaciones Geográficas, n² 22. pp. 95-107. Cf. p. 96. 
matas sardonales y bardales respectivamente. Cuando se ha querido compaginar el aprovechamiento del vuelo como el del suelo como pastizal se ha aclarado la masa: monte hueco de la dehesas. Igualmente en éstas para renovar los árboles viejos, una vez cortados, se han seleccionado los brotes por brinzales, los resalvos, que alineados en lo posible se han convertido en encinos durante cinco lustros para después ser encinares de pasto, labor y monte, que recientemente se le ha dado el cursi nombre de explotación agrosilvopastoril ${ }^{19}$.

Siempre ha habido montes que, después de una explotación abusiva, se les ha dejado abandonados a su aire durante bastante tiempo; pronto se convertían en inextricables, hasta que les llegase el momento de la entresaca para emprender de nuevo otra más racional. Eran los arcabucos; hoy con el abandono y los cambios en la economía rural son una de las formaciones más abundantes en encinares y quejigares.

Nombres todos éstos, lígrimos del español, que expresan la fisonomía de masas y elementos de la vegetación. Si no son tan abundantes en los montes maderables no por ello dejan de llevar una huella indeleble de la acción antropogénica. Para su explotación se ha alterado la primitiva masa vegetal con aclareos, caminos de saca y trochas de acceso. Se ha pasado así del monte bravo al oquedal. Mediante podas u otras técnicas se ha favorecido el crecimiento y rectitud de sus troncos. También para el mejor logro de estos fines se ha rozado el monte, y más en el pasado que en el presente. Pues el matorral era la base de la leña menuda hornija o támara y la hojarasca materia prima para obtener estiércol. Se ha alterado así la masa primitiva tanto en su vuelo como en su suelo.

Por todas estas técnicas, cuando no por plantación directa, no sólo se han conservado las masas de vegetación, sino que llevan la inequívoca impronta de la acción humana. Tienen más de comunidades antropogénicas que de naturales. En este último aspecto lo son, porque su desarrollo, aunque dirigido, se deja a la acción espontánea de lo ecológico. Se da, por tanto, la paradoja de que la veste vegetal, que se considera como la expresión más genuina de la naturaleza, es un paisaje humanizado.

$\mathrm{Su}$ estudio de este modo, que yo considero como el más geográfico, entra dentro de la concepción antropocéntrica de la que no se puede desprender la geografía. El campo, vuelvo a iterar, que se le abre, además de nuevo, es muy grande. Sin embargo, poco, o casi nada, se ha hecho en este aspecto; y los geógrafos siguen empecinados en seguir los pasos de los botánicos. Es difícil romper la inercia; pero alguna vez habrá que hacerlo. Mientras tanto hay que considerar a la biogeografía versus botánica.

La geografía física parece diluirse, por tanto, en una serie de geografías independientes, que se funden con las ciencias naturales. Es más, así como los geomorfólogos se dicen afines con la geología, los geógrafos dedicados a las otras geografías físicas confiesan, que ellos están más cerca de las ciencias de la naturaleza, que no de la geografía en cuanto tal, como ciencia social, que es lo mismo que decir, geografía humana. Pero esto no deja de ser un eufemismo; porque no están cerca, sino dentro de ellas. Se comprende, que la geografía física haya perdido entidad. Lo demuestra que, aspectos que pertenecen a ella, en la enseñanza secundaria sean considerados propios de geólogos y biólogos. Algo análogo ocurre en los informes y en los estudios del llamado medio físico. La geografía física simplemente no existe, a no ser en la mente de los geógrafos. Son ellos los que, al introducirse en las llamadas ciencias afines, han contribuido a que desaparezca.

19 Sobre la técnica de poda de encinas, su porte, y su renovación hay información interesante en FUENTES SÁNCHEZ, C. (1999): La encina en el Centro y Suroeste de España. Junta de Castilla y León. Conserjería del Medio Ambiente y Ordenación del Territorio, 238 pp. 
De todo esto se puede llegar a la conclusión de que no hay una geografía física. No lo juzgo yo así; si de este modo pensase no estaría haciendo estas reflexiones. Porque es evidente, que el relieve es una forma primaria de la superficie terrestre; que en cada territorio hay un ambiente permanente del que no se puede prescindir, y que no queda más remedio que estudiar, no como climatología, sino como análisis geográfico del clima; que también hay una circulación de las aguas en el más lato sentido; así como un paisaje vegetal, aunque en su estado actual sea un producto de la acción humana. Son los elementos del llamado medio físico o medio ecológico, a pesar de que no se comprenda como un todo, sino mediante estudios independientes. Esto es lo que justifica la geografía física dentro de la geografía. Idem sed aliter. Aquí es en donde están las conclusiones a las que yo quiero llegar.

\section{Geografía Física y Geografía}

Si al principio del artículo la enuncié como geografía física o ciencias naturales, ahora la truco por la de Geografía física y geografía, porque ambas de modo inmanente son parte de un todo, la superficie terrestre, y ambas tienen relaciones recíprocas. Acabo de afirmar que el medio físico o ecológico es lo que justifica a la primera; será el punto de partida.

Pero éste, como todo lo geográfico, es algo complejo, muy complejo; y cuando hay complejidad hay jerarquización: uno hechos aparecen subordinados a otros. Entre los hechos físicos de la superficie terrestre hay uno, que no queda más remedio que alzaprimar. Este es el relieve, no porque sea la forma primaria, y más perceptible de ella; sino porque es el elemento desencadenante; pues a él están subordinados todos los demás. En efecto, modifica el clima a escala regional y local. Los tipos de tiempo se dejan sentir de modo diferente según su configuración. Basta pensar sólo en los grandes conjuntos climáticos para confirmarlo.

Relieve y clima, por lo que a las precipitaciones se refiere, originan la circulación de las aguas en el más amplio sentido. En las montañas es en donde nacen, y adquieren su verdadero carácter, las principales arterias fluviales, que después cruzan otras áreas muy diversas a las que principalmente benefician. En ambas actúan las aguas de escorrentía que, a su vez, originan el complejo absorbente, la circulación de las aguas subálveas, y la de las hipógeas de acuerdo con las litofacies en la estructura que va vinculada al relieve.

Unas y otras de consuno son las que determinan los procesos erosivos actuales; al igual que en el pasado, bien sea en relación con redes heredadas del Pleistoceno u otras anteriores que hoy no son funcionales. Son estos procesos de tiempos pretéritos los que han originado las formas de modelado, bajo otras condiciones ecológicas, que hoy constituyen los detalles o modificaciones importantes de los elementos del relieve. Hay que pensar que, si bastantes de nuestras montañas hoy presentan un modelado glaciar, fue porque durante los periodos fríos del Pleistoceno por su altitud, condigna con su formación, se encontraba en el tramo en el que el frío intenso hacía que el agua actuara como hielo.

Relieve-clima-circulación de las aguas son elementos abióticos, permanentes, sólo de un modo muy leve susceptibles de ser modificados por la acción humana. Pero todos al unísono crean unas condiciones ecológicas variadas y un complejo ecológico, que han dado también resultado de modo diverso, a unos distintos tipos de vegetación. Y éstos de consuno con todos los demás, a los suelos en el sentido edáfico; y no a la inversa, como se enuncia generalmente. Pues éstos a su vez son los que mantienen a la vegetación; constituyen, valga la expresión, su despensa con los nutrientes que proceden de ella. 
Sin embargo, en este aspecto biótico, no hay que caer en el mecanismo ecológico, que he señalado, sino considerarlo con cierta flexibilidad. Desde luego es un elemento a tener en cuenta, porque no vamos a encontrar abedulares en las llanuras de Castilla; ni robledales en las montañas levantinas. Unas y otras masas de vegetación se encuentran en donde las condiciones les son aparentemente más propensas; pero no siempre. Para evitar semejante mecanismo ecológico hay que tener en cuenta dos factores.

El primero son las aportaciones de la paleobotánica, que es lo mismo, que la historia natural de la vegetación. Mediante ella se puede comprender esas llamadas comunidades relictas, como los hayedos de la vertiente meridional de la Cordillera Cantábrica, casi en el contacto con la Castilla de las Llanuras o los de la Ibérica (Valdelaguna), donde se han adaptado desde hace milenios, a pesar de haber una sequedad estival; y no sólo perviven, sino que medran; y en los momentos actuales de un modo sorprendente. Otro tanto, cabe decir, para los encinares en plena España Atlántica (Liébana y Ribamontan al Mar entre otros lugares) de veranos húmedos y brumosos.

El segundo factor, que ya he antuviado, en parte, es la historia humana de la vegetación que, por interés económico, se ha favorecido unas especies arbóreas sobre otras. Tal es el caso de las nebredas o enebrales de Juniperus thurifera a costa de encinares y quejigales en las parameras de la Cordillera Ibérica o de los pinares de pino silvestre, reemplazando a los rebollares en esta Cordillera o en la Central (Puerto de Navacerrada y del Alto del León).

Sin embargo, estos aspectos que añaden más complejidad a lo que ya de por sí es complejo, no son más que excepciones, que, valga el tópico, confirman la regla. Una regla, que se rige por la subordinación y jerarquización en la cual el relieve, el gran olvidado de la geografía con sus morfoestructuras, es el elemento desencadenante. De este modo el medio físico no sólo justifica la geografía física, sino que le da sentido dentro de la geografía. Es una geografía física integrada en la que los distintos elementos aparecen lañados por recíprocas relaciones. Pero en esto nada tiene de particular, porque toda la geografía es integrada.

Pero es que, además, con esta dialéctica el medio físico, al convertirse en medio ecológico, trasciende a toda la geografía, aunque más como complejo ecológico, entendiendo por tal la relación relieve-clima-hidrología en su más amplio sentido, pues siempre, aunque sea por uno de sus resquicios, ha sido valorada para la actividad agraria, y en los momentos actuales para superar sus dificultades es igualmente un elemento de cuenta en esta actividad piénsese en la insolación en los cultivos de ciclo manipulado u otras actividades como el turismo en la fachada mediterránea y meridional de España y en los tipos de turismo y poblamiento temporal de estío en las montañas, cuando no en el coste de las infraestructuras por ejemplo el TVA de Madrid-Valladolid.

De este modo, el medio-complejo ecológico es uno de los factores del territorio organizado. La geografía física pierde así esa concepción antropocéntrica, que anuncié al principio, y que es ínsita de toda la geografía; e incluso se funde con ese paisaje humanizado, que igualmente anticipé como paisaje vegetal, embalses, bancales de áreas montañosas, etc. son otros modos de valoración-superación del medio físico-ecológico.

Sin embargo, esta dialéctica de la geografía física requiere dos observaciones. Esta es la coda final.

El estudio de estos elementos en sus relaciones de jerarquización subordinación como un todo a la vez, es el estudio de lo concreto, y lo concreto es lo variado y múltiple, sólo se puede hacer a escala regional. Abstraídos los elementos de su contexto al modo de la 
geografía general académica, pierden su trabazón. De ahí, que esta geografía física de elementos integrados refuerza el carácter de geografía regional, que es inmanente a la geografía.

Este modo de concebir la geografía física no es incompatible con la geografía física académica, sino que ambas se complementan. No se trata de sustituir éstas por aquélla. No he pensado nunca en esto. Sí he criticado los desmanes de sus cultivadores, que en vez de considerarse partes de un todo, se han convertido en todos a parte, e incluso fuera de la geografía. Pero no he negado, ni su utilidad, ni su necesidad, ni tampoco que se realicen investigaciones sectoriales. Pues sin conocer los elementos aislados en sus variedades, con sus características propias y las causas a las que responden a la escala de la superficie terrestre, es imposible llegar a la trabazón que tienen entre sí en un territorio concreto. La geografía general física académica tiene una finalidad propedéutica inexcusable. Es la base de la formación del geógrafo.

Esto no hace más que confirmar, que por su complejidad, la geografía es un modo de conocimiento difícil. Pero la superficie terrestre es así, y si se quiere abordar en su verdadera realidad no queda más remedio que esforzarse y reflexionar mucho. Aquí viene a colación el refrán castellano de «a bragas enjutas no se pescan truchas».

Valladolid, 20 de Octubre del año 2000.

\section{Bibliografía}

BELMONTE SERRATO, F., ROMERO DÍAZ, A. y LÓPEZ BERMÚDEZ, F. (1999): «Efectos sobre la cubierta vegetal, la escorrentía y la erosión del suelo, de la alternancia de cultivo abandono en parcelas experimentales» en Investigaciones Geográficas, $\mathrm{n}^{\circ}$ 22. Instituto Universitario de Geografía. Universidad de Alicante, pp. 95-107.

BERTRAND, G. (1968): «Paysage et geographie physique globale. Esquisse methodologique», en Revue Geographique des Pyrénnés et du Sud-Ouest, T.39. pp. 249-272.

BLANCO CASTRO, E. (1997): Los bosques Ibéricos: una interpretación geobotánica. Ed. Planeta. Barcelona, 572 pp.

BOUHIER, A. (1979): La Galice. Essai geographique d'analyse et de interpretation d'un vieux complexe agraire. La Rochesur-Yon (Vandée). 2 vols.

CASTILLO REQUENA, J. (1981): «Mecanismos de precipitación en Sierra Nevada», en Cuadernos Geográficos, $\mathrm{n}^{\circ}$ 11. Universidad de Granada, pp. 127-152.

CLAVERO PARICIO, P. (1983): «Probabilidades de precipitaciones intensas en diversos observatorios de Cataluña» en Notes de Geografía Física, no 9; Barcelona, pp. 33-38.

CLAVERO, P., MARTÍN VIDE, J. y RASO, J.Ma . (1982): «La climatología actual: el uso de métodos estadísticos y modelos probabilísticos» en Notes de Geografía Física, Barcelona, pp. 510.

CUADRAT, J.Mª.y PITA, Ma F. (1997): Climatología. Ed. Cátedra. Madrid, 496 pp.

DÍAZ FIERROSVIQUEIRA, F. (1971): Contribución a la climatología agrícola de Galicia. Universidad de Santiago de Compostela. 110 pp.

FONT TULLOT, I. (1988): Historia del clima en España. Instituto Nacional de meteorología. Madrid, $297 \mathrm{pp}$.

FUENTES SÁNCHEZ, C. (1999): La encina en el Centro y Suroeste de España. Junta de Castilla y León. Conserjería del Medio Ambiente y Ordenación del Territorio. 238 pp. 
GARCÍA RUIZ, J.M. (1999): La producción científica de la geomorfología española y su impacto a través de las publicaciones periódicas. Instituto Pirenaico de Ecología. CSIC. Zaragoza, $104 \mathrm{pp}$.

GIL OLCINA, A. y OLCINA CANTOS, J. (1997): Climatologia General. Ed. Ariel. Barcelona, $579 \mathrm{pp}$.

GÓMEZ MENDOZA, J. (dir.), MATA OLMO, R. et al. (1999): Los paisajes naturales de Madrid: naturaleza y medio rural. Fundación Caja Madrid. Alianza Editorial. 301 pp.

GONZÁLEZ BERNÁLDEZ, F. (1981): Ecología y paisaje. Ed. Blume. Madrid, 250 pp.

HART, M.G. (1986): Geomorphology pure and applied. George Alle and Urbin. Londres, $228 \mathrm{pp}$.

KLARK, M.J. et al. (1987): Horizonts in physical geography. McMillan. Londres, 395 pp.

LE ROY LADURIE, E. (1991): Historia del clima desde el año mil (Trad. de francés de 1983). Fondo de Cultura Económica. México, 515 pp.

LÓPEZ GÓMEZ, A. (coord.), FERNÁNDEZ GARCÍA, F., ARROY ILLERA, F., MARTÍN VIDE, J. y CUADRAT, J.Mª. (1993): El clima de las ciudades españolas. Ed. Cátedra. Madrid, 262 pp.

MARTÍN VIDE, J. (1990): «Las técnicas cuantitativas en geografía física española de los años 80. Una aplicación al cálculo de probabilidades en climatología» en IV Coloquio de Geografía Cuantitativa. Palma de Mallorca. pp. 299-310.

MARZOL, Ma V., DORTA, P. y VALLADARES, P. (eds.) (1996): Clima y agua. La gestión de un recurso climático. Ed. Tabapress. Madrid, 398 pp.

ORTEGA VILLAZÁN, M ${ }^{\mathrm{a}}$ T. (1992): El clima del sector Norte de la Cordillera Ibérica. Estudio geográfico. Universidad de Valladolid, $359 \mathrm{pp}$.

RASO NADAL, J.Ma y MARTÍN VIDE, J. (eds.) (1999): La climatología en los albores del siglo XXI. Asociación Española de Climatología. Barcelona, 587 pp.

RIVAS MARTÍNEZ, S.: Mapa de series de vegetación. ICONA.

VV.AA. (1998): Paisaje y medio ambiente. Universidad de Valladolid, $150 \mathrm{pp}$. 